\title{
AGENT-BASED SIMULATION OF MEASURING THE QUALITY OF SERVICES
}

\author{
Biserka Runje, Elizabeta Krstić Vukelja, Josip Stepanić
}

Original scientific article Quality level, achieved by a service-providing company, has complex dynamics. It is demanding to optimise the company's performances in a realistic, non-characterised environment. This article contributes to stated optimisation by formulating the agent-based model for performance of a service-providing company. A set of elements and relations representing a structure of such a company is described and explained. In addition, some elements occurring in realistic situations are not included in the model and their absence is explained. Parameters of the model are divided into two groups. First group consists of parameters describing interactions between the company and its environment and second group of the parameters describing internal interactions among the company's elements. Interactions are represented using time-dependent information entropy. Quality of the company's performances is related to values of accompanying information entropies. Relatively simple agent-based model makes possible reliable representations of a variety of observed functions of service companies.

Keywords: agent-based model, information entropy, measuring quality, service providing company

Simulacija mjerenja kvalitete usluge primjenom modeliranja pomoću agenata

Izvorni znanstveni rad

Razina kvalitete, što ju postiže tvrtka koja pruža usluge, kompleksne je dinamike. Zahtjevno je optimiranje performansi tvrtke, u stvarnoj, nekarakteriziranoj okolini. U ovom radu doprinosi se navedenom optimiranju primjenom modeliranja pomoću agenata primijenjenog na performanse tvrtke koja pruža usluge. Skup elemenata i relacija, koje predstavljaju strukture takove tvrtke, je opisan i obrazložen. Dodatno, neki elementi koji se javljaju u stvarnosti nisu uključeni u model što je također obrazloženo. Parametri modela podijeljeni su u dvije grupe. Prvu grupu čine parametri što opisuju interakcije između tvrtke i njene okoline, a drugu grupu parametri koji opisuju interakcije između elemenata tvrtke. Interakcije su predstavljene pomoću vremenski ovisne informacijske entropije. Kvaliteta rada tvrtke povezana je s iznosima pripadnih informacijskih entropija. Relativno jednostavni model temeljen na agentima omogućava pouzdano reprezentiranje niza uočenih djelovanja tvrtki koje pružaju usluge.

Ključne riječi: informacijska entropija, mjerenje kvalitete, model temeljen na agentima, tvrtka koja pruža usluge

\section{Introduction}

One of the ways, with which a service-providing company can optimise the quality of its services, utilises simulations based on validated models of market dynamics.

Successful functioning of a company within a modern, global and complex, highly-competitive market benefits from detailed understanding of dynamics of various, mutually connected and influencing elements and processes. Optimising quality using thoroughly developed quality management approaches has become a highly complex, constantly conducted company's activity. One of the methods to achieve sufficient understanding of stated dynamics is by modelling the essential parts of the market, the company and its environment, accompanied with the extensive numerical or other type of simulations, followed with the analysis and interpretation of obtained results and its constant linking to existing measures of quality.

The underlying reason for importance of simulation models is that complexity of modern markets many times exceeds human capabilities for reliable, founded analysis and planning. While sharing some similarity, successful market entrances are partially unique and innovative.

Simulating functions of various types of companies has been conducted since long time ago. Corresponding simulations utilise system dynamics, neural networks, agent-based modelling and other modelling methodologies. We extract the agent-based modelling $(\mathrm{ABM})$ as a methodology which allows that structure of the model resembles the structure of realistic institutions and organisations, and which furthermore allows defining the variable number of categories/agents including large number of individual agents, contrary to other listed methodologies $[1,2]$. In this article we utilise definitions as given elsewhere [1]. ABM has been applied to describe various commercial services $[3 \div 5]$. Baxter, Collings and Adjali use $\mathrm{ABM}$ to formulate customer relationship management approach [3]. They demonstrate higher quality of their approach when compared with other types of modelling, especially macroscopic modelling that uses aggregated data about (potential) customers. Their model includes customer dynamics and within it the spreading of information about the company within the population of customers. Kaihara uses ABM to study supply chain in case of highly dynamic environment of customers [4] and demonstrates, for the formulated model, the existence of optimal way to allocate the products. Terano and Naiteh formulate and validate ABM for market of competing companies related to television programmes and audio cassettes [5]. Agents represent companies, and align their behaviour in an auto-referential way using time-dependent data. Kočiško et al. concentrate onto software models for production companies with emphasis put onto their applicability in the contemporary society as characterised with drastic transformations of economic landscape [6]. An initial development of concept underlying applications of $\mathrm{ABM}$ to service-oriented institutions was developed by Krstić Vukelja and Runje [7]. Their approach was based onto recognition of importance of feedback loop in providing services. The loop relates service-providing company and end-users with the following two relations: one is the service being provided by the company and the other is the attitude about the service (and generally about the company) developed by end-user. That attitude has its own dynamics, influencing 
possible other end-users and figuring as a natural source of information which is in fact of ultimate relevance for the future company's functioning.

Agent-based models that simulate functioning of service-providing companies are not sufficiently developed. There are no simulation models which are both sufficiently robust regarding the characteristics of the environment and sufficiently sensitive regarding the variation in characteristics of customers, i.e. end-users of services offered.

Furthermore, since quality of a service is a cornerstone of predicting or characterising a market dynamics of a company's it is natural to represent quality and its components within the model, thus enabling the researchers or practitioners to concentrate on simulated dynamics, or on dynamics of quality, or both.

In this article we formulate agent-based simulation model of a generic service-providing company. The formulated $\mathrm{ABM}$ is robust regarding the characteristics of environment which includes company's societal and natural environment. However, it is sensitive to variations of end-user characteristics at the individual level. We implement the indicators and measures of quality in the model and prescribe their dynamics.

However, a problem closely related to introduction of modelling methods is which set of parameters should be used to meaningfully express the important company's characteristics, such as its capability, its market potential, overall - its quality. Regarding that problem, we introduce a scalar quantity, information entropy and define it at the level of company's dynamics. Suitably averaged, it represents the overall quality of the company, expressed either generally or with focus on part of a company's functioning $[8,9]$. For example, Liu and Zhang project company's competitiveness onto its supply chain management and utilise information entropy weight to compare success of a particular decision [8]. Other authors emphasise the dynamics of supply chain, yet utilise different methodologies in cases of more general flows [10].

Similarly, Zhang et al. use information entropy eight to establish ranks within the set of companies providing touristic services [9]. These are particular cases of a more general approach to characterise and compare diverse processes in societal environments using information entropy or its equivalents $[11,12]$. The corresponding general methodology of attributing information entropy and related measures to a dynamic of some complex system is described in [11]. In addition, in [11] the authors listed a set of indicators in use for measuring the complex quantities characterising quality of functioning of a general societal system, including service-providing company. The application of the developed methodology onto the system of donations was treated in details by Kasač et al. [12]. Donations are attributed with formally somewhat simpler dynamics than that of commercial providing of services, yet of more heterogeneous character since it involves different aspects of involved parties.

Second section contains description of the model. Third section contains preliminary results and the analysis of possible validation of the model. Fourth section summarises and concludes the article.

\section{Model}

In this section, the agent-based model for describing essential dynamics of quality of a commercial service-providing company is formulated.

The model emphasises one company, serviceprovider of otherwise unspecified characteristics. The company functions within a commercial, competitive market characterised by known and shared companyrelated information within the end-user society. The existence of other companies is implicitly assumed, thus they are not modelled explicitly.

Elements of the model are the two types of agents, the environment and the rules. First agent type includes company's departments. Second agent type represents end-users. Depending on the particular realisation, the second type may refer to unspecified ratio of individual and collective end-users. Environment consists of company's raw materials providers, and of general implicitly specified market. Rules in the model define the dynamics on the micro-level and consist of the following types: (i) rules governing agent-agent interactions, (ii) rules governing agent-environment interactions and (iii) rules governing internal environment interactions. The rules are described along with the introduction of agents. In a separate sub-section we attribute a set of micro- and macro-level indicators to the model.

\subsection{First Agent Type}

Company's departments need to be treated explicitly as separate entities since modern companies generally consist of several units differing in physical locations, organisational structure, field of expertise etc. Thus, the production unit, distribution unit, customer-relations unit, quality management unit and also the subcontractors, temporary established franchises etc. are of this type.

In order to represent the essence of organisational structure, we consider two agents of the first type: one is the agent that represents department performing the service and the other is the agent representing the quality management department. Variables have index $p(q)$ if they refer to the former (later) agent. The following time-dependent functions are attributed to the first agent: quantity of resources spent in a given time unit $r_{p}$, number of services started in a given time unit $s_{p}$ and the capability function of the agent $c_{p}$ (in all functions, time dependence is suppressed for clarity). These functions are modelled in such a way that they contain further parameters and sub-functions which are addressed further in details further in this sub-section.

It is assumed that the first agent can perform $N$ services per time unit. Quantity $N$ includes both the newly provided services and the continuation of services the conduction of which started in some previous time unit. Let $h(k, \delta)$ denote number of services needed in the $k^{\text {th }}$ time unit by people who already wait $\delta$ time units. It must be stressed that number of people asking for a service in the $k^{\text {th }}$ time unit, $n(k)$, is assumed to be a stochastic variable, the distribution function of which is Poisson 
distribution. Finally, if more services are asked for than the company can provide then a definite quantity, denoted here as $x(k)$ counts number of services which will be provided in future. Thus one obtains the following constitutive relation

$N=n(k)+\sum_{\delta=1}^{k-1} h(k, \delta)-x(k)$.

Quantity of resources spent, $r_{p}$, depends on the characteristics of the $N$ services provided. That quantity is modelled following the distribution of resources that are needed for a single service. Distribution of resources attributed to a single service follows a truncated normal distribution with average value $\bar{r}_{p}$ and standard deviation $\sigma_{r}$ and achievable values ranging from 0 to some introduced amount $R$. Thus, $r_{p}$ is the sum of $N$ values generated by the stated truncated normal distribution.

Capability function is derived from the average level of knowledge $(K)$ of personnel in that agent, from the total number of working personnel $(P)$ and from the existing infrastructure and equipment in function $(E)$ :

$c_{p}=(K+E) \cdot P$

for which it is implicitly assumed that all of the personnel shares equal and sufficient competences.

Before proceeding let us emphasise that capability influences number of services provided in one time unit in the following way

$$
N(k)=N_{0} \frac{c_{p}(k)}{c_{p}(1)},
$$

in which constant $N_{0}$ is the referent number of service provided in one time unit. In the simulations, it is implemented as $N(1)$.

Depending on the choice of measuring units, one can expect that auxiliary constant appears in (2) in order to align possible differences in measuring units. Here we assume all the scalar quantities to be measured using the same measuring unit. Furthermore, we treat $K$ and $E$ as non-dimensional parameters in the range from 0 to 1 . In particular, $E$ equals 1 if all equipment is functioning and all infrastructures are utilised in providing services. Depending on the deviation of real situation from that idealised state, quantity $E$ is lowered by proper amount. On the other hand, $K$ is obtained by summing the knowledge level of a particular person from the agent's personnel with prescription that $K=0$ for a novice, $K=1$ for a person with sufficient experience and $K$ linearly dependent on experience in the range from $K=0$ to $K=1$. Value of $P$ is directly the number of currently working personnel. If it changes it is for finite amounts, the least being 1 . Decline of $P$ by 1 is caused by absence because of starting the annual leave, sick leave or other kind of temporary leave, or by retirement or resignation. Growth of $P$ by 1 occurs after finished annual leave, sick leave or other kind of temporary leave, or after employment of a new person to already employed personnel.
Dynamics of $K$ reveals two different contributions. One is gradual rise, a drift because as time passes all personnel acquire additional experience. Another is sudden change, either decline or growth. The sudden change of $K$ is to be differentiated from sudden change of $P$, and it occurs when after a novice is employed after retirement or resignation of a more experienced person. We model dynamics of $K$ as follows:

$$
K(k+1)=(1+r) \cdot K(k)-R_{-} \cdot \Delta_{-}(k+1)+R_{+} \Delta_{+}(k+1),
$$

where $k=1,2, \ldots$ is time unit, $r<<1$ is rate of gradual rise in personnel knowledge level, $R_{-}$is the difference in levels of knowledge between an expert and a novice, while $\Delta$ is integer variable of values either 0 or 1 , following Bernoulli distribution. Corresponding probability for occurrence of value $\Delta_{-}=1$ is considered as a rather small value. Furthermore, $R_{+}$is the finite value representing improvement of $K$ because of additional training, consultations etc. The variable $\Delta_{+}$will be defined later as it is derived based on the functioning of other agent of first type.

We assume that changes in $E$ are of stochastic character in such a way that smaller changes in $E$ occur more often but are of shorter duration, while larger changes in $E$ are relatively large yet of considerably larger duration. Since $E$ is a measure of functionality of a collection of equipment and infrastructural units, one may argue that proper distribution of its values in different time units is truncated normal distribution with average value $\bar{E}_{p}$ such that $0<\bar{E}_{p}<1$ and standard deviation $\sigma_{E_{p}}$ and interval of achievable values ranging from 0 to 1.

Separate parameters describe the other agent of first type, the representation of the quality management department. That agent presumably deals with pieces of information: one type of information is information gathered from the population, the real or potential users of services and the other type of information denotes commands and/or suggestions sent to first agent.

Information gathered from the population consists of results of surveys and questionnaires which are conducted from time to time. We will assume that in every time unit that agent obtains a finite number of filled questionnaires from the users of their services. After analysis, questionnaires reveal some trends in end-users' attitudes toward services. Attitudes, $A$, are represented as variable between 0 and 1 and are assumed extracted from a set of questionnaires in one time unit. We do not model details of the data collecting. The attitudes are modelled in this model as consisting of two parts: a part functionally derived from other quantities and a stochastically generated part. Functionally derived part is consequence of capability level of first agent, while stochastic part is normally distributed:

$$
A(k+1)=\tanh \left[(1+\alpha) \cdot c_{p}(k)\right] \text {, }
$$

where $\alpha$ is auxiliary variable, distributed normally with the average 0 and standard deviation $\sigma_{\alpha}$. Based on the value of $A$, in the next time unit the quality management 
department i.e. agent two of first type, formulates notes to agent one. If $A$ is smaller than some referent value $A_{0}$ then notes ask for improvement of capability $c_{p}$. Here we consider $A_{0}$ to be a constant.

In realistic situations notes are accompanied with underlying discussions, planning and their distributed implementation. In general, such processes are to be modelled as improvement in $K, E$ or $P$. However, for simplicity we assume that the improvement takes place only by sudden raise in $K$, as described in (4) through the part $R_{+} \Delta_{+}$, with

$\Delta_{+}(k+1)=\frac{1+\tanh \left[A_{0}-A(k)\right]}{2}$.

\subsection{Second Agent Type}

Agents of second type are numerous agents that share the set of determining parameters yet differ in values of these parameters. We assume that a definite probability distribution covers well a set of those values.

These agents are assumed to have some unspecified goal that requires certain amount of services to be used from time to time.

The time-dependent characteristics are attributed to each and every of these agents:

- the sum they have and are willing to spend on the service $s_{i}(k)$,

- probability that they ask for service in a given time unit, $p_{i}^{\alpha}(k)$,

- duration of waiting between asking for and obtaining of the (final part of) service, $\tau_{i}^{\alpha}(k)$,

- their evaluation of the quality of the service obtained.

In listed characteristics, index $i$ denotes an agent, superscript $\alpha$ refers to the type of the service, all in the kth unit of discrete time. These characteristics are assumed to be distributed in accordance with the Poisson distribution. Their mean values, denoted as $\bar{s}, \bar{p}^{\alpha}$ and $\bar{\tau}^{\alpha}$ respectively, are assumed to be time-independent. Evaluation of quality is treated differently as it has been already included in the formation of attitude $A$ by quality management department, one of the agents of first type.

\subsection{The Environment}

Environment dynamics incorporates internal processes within end-user system. It is implicit in the model, incorporated it in the stochastic changes of $E$ and of $A$. In particular, rate of receiving materials needed for services influences $E$, then societal misconceptions and ambiguities about some service-providing company may influence attitudes toward it and may, furthermore, influence number of population asking for the particular service, denoted previously as $n(k)$.

\subsection{The Indicators}

After a model is software-implemented and numerically simulated, one obtains a number of time-dependencies, of average resource consumption, average waiting-time, average attitude as inferred from questionnaires, etc. Whether dynamics is within acceptable range or not depends on externally imposed conditions and may differ for various quantities shown. Since different contexts impose different criteria, it is more opportune to relate quality of service in a reliable way to internally derived quantity. That quantity spans a unique scale enabling interested parties to compare quality of work of different service-providing companies.

We represent the quality of services performed using information entropy weight (IEW). Its basis is information entropy $S[11 \div 13]$. It is a functional that is evaluated for an arbitrary function $f(k)$ defined in the model, and determined for a given time interval ranging from the $k^{\text {th }}$ to the $(k+\kappa)^{\text {th }}$ time unit, thus $S=S[k, \kappa, f(\cdot)]$. Prior to determining $S$, one must estimate the probability distribution function of values $y$ that function $f$ achieves within a given time interval ranging from the $k^{\text {th }}$ to the $(k+\kappa)^{\text {th }}$ time unit. If we denote that distribution function as $p_{\mathrm{f}}(\{y\} ; k, \kappa)$ then it follows

$S[k, \kappa, f(\cdot)]=-\int p_{f}(\{y\} ; k, \kappa) \ln p_{f}(\{y\} ; k, \kappa) d y$.

The integration in (7) is substituted with summation if there is a finite number of different values $y$.

\section{Results}

Model formulated by $(1) \div(7)$ has to be validated. It is by no means trivial and requires testing the predictions of the model with a representative data from various areas of applications.

Yet, generic situations may be analysed using synthetically obtained data. The analysis of results obtained contributes to validation. For that purpose, we simulated the model using average number of $\bar{n}=50$ services asked for within one time unit, initial number of services $N=55$, fixed level $E=0,6$ with initial level $K=0,4$ and referent personnel number $P=5$. Fig. 1 shows time dependence of number of agents asking for a service in a given time unit (first two parts of right hand side in (1)) as well as number of agents who need to wait to obtain service in later time units, i.e. $x$ in (1).

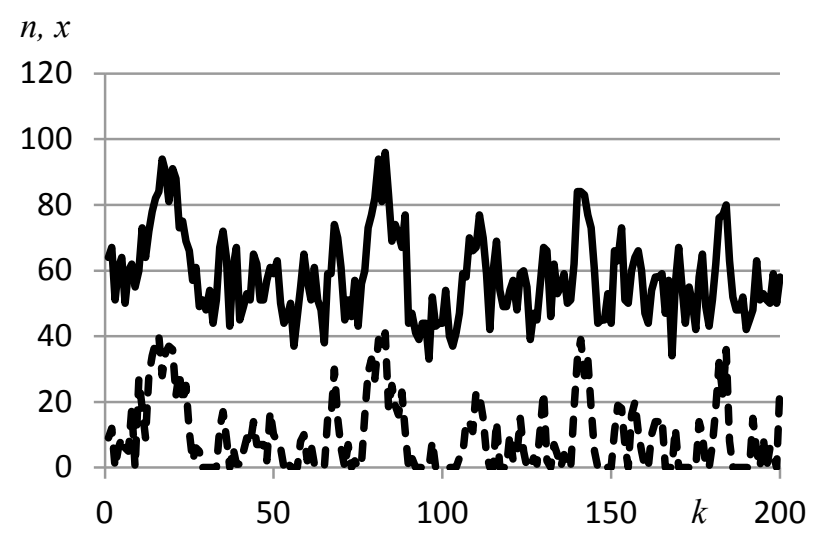

Figure 1 Number of agents asking for a service in a given time unit (bold line) and number of agents who did not obtain the service in the same time unit in which they asked for it (dotted line). 
Change in the needed average level of knowledge is calculated using (4) for particular case in which $R_{-}=0$ and $R_{+}=1$, Fig. 2. That change is implemented in (2), thus modifies number of services provided in one time unit (3). Implicitly in obtaining graph shown in Figure 2 is evaluation of questionnaires which are assumed obtained. In this case we set that 5 independent attitudes are obtained in each time unit with range in their amounts as previously described. It is not considered further how that needed change will be implemented, whether in several time units part by part, or completely in one, e.g. the next time unit.

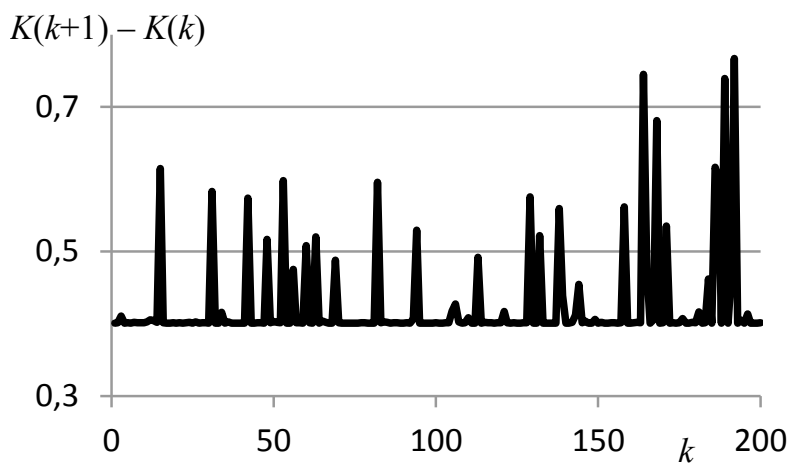

Figure 2 Time dependence of needed change in average level of knowledge.

In this case we considered that needed change (a rise) in the average level of knowledge is performed completely in the single time unit, first after the change is determined. That corresponds to a perfect response and is certainly an idealisation. Its character of a limit makes it a suitable benchmark test in further work, when we will treat more realistic, non-perfect induced changes of the average level of personnel's knowledge $K$.

We evaluate information entropy of time-dependent set of average end-user attitudes. Averaging window span $\kappa=5$ time units. Probability distribution function of corresponding distribution of values of attitudes is determined by fitting the 5 averages to normal distribution with expectation $\mu_{\mathrm{A}}$ and standard deviation $\sigma_{\mathrm{A}}$ :

$$
\begin{aligned}
& p_{\mathrm{A}}\left(\left\{A_{k}, \ldots, A_{k+\kappa}\right\} ; k, \kappa\right)=p_{\mathrm{A}}\left(\left\{A_{k}, \ldots, A_{k+5}\right\} ; k, 5\right), \\
& p_{\mathrm{A}}\left(\left\{A_{k}, \ldots, A_{k+\kappa}\right\} ; k, \kappa\right) \rightarrow \mathrm{N}\left(\mu_{\mathrm{A}}, \sigma_{\mathrm{A}}\right) .
\end{aligned}
$$

In case of a normal distribution, the information entropy can be calculated analytically:

$$
S\left[k, 5, p_{\mathrm{A}}\left(\left\{A_{k}, \ldots, A_{k+5}\right\} ; k, 5\right)\right]=\ln \left(\sigma_{\mathrm{A}} \sqrt{2 \pi}\right)+\frac{1}{2},
$$

from which it is seen that information entropy accompanying attitude distribution is a function of the standard deviation of attitudes,

$\Delta S=\ln \sigma_{\mathrm{A}}$

Thus it suffices to show the typical time-dependence of the natural logarithm of standard deviation $\ln \sigma_{\mathrm{A}}$ in Fig. 3 in arbitrary units. Graph in Fig. 3 reveals two characteristic contributions to dynamics of $\ln \sigma_{\mathrm{A}}$ and correspondingly to dynamics of information entropy attributed to dynamics of end-user average attitudes: one contribution to dynamics originates in rare and large deviations of underlying attitudes. The other contribution is realised as constantly occurring relatively small changes. With different coarse-graining window $\kappa$ the relative intensity of changes would differ from that seen in Fig. 3, however the two separate contributions to overall change would be present.

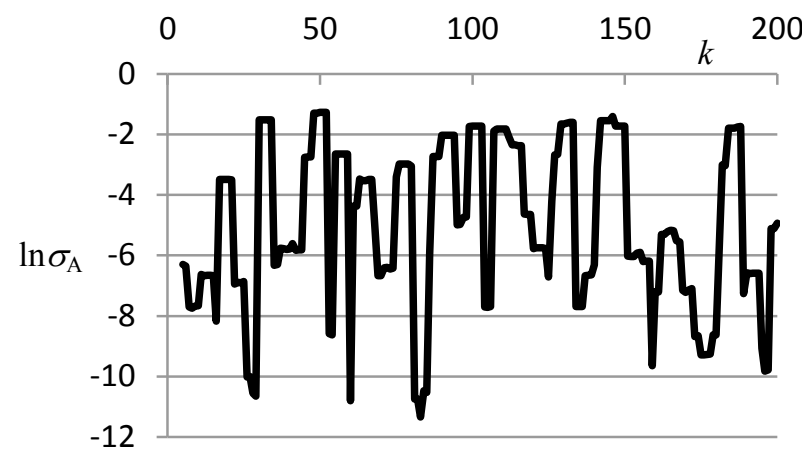

Figure 3 Time dependence of standard deviation attributed to end-users' attitudes toward service.

Similarly to information entropy of average end-user attitudes one can determine information entropy of other (time-dependent) quantities representing the model dynamics. Thereby obtained set of information entropies functions as a set of coarse-grained indicators of the quality of the system. It is expected that smaller information entropy marks more precise implementation of the quality related measures and stronger link between the quality level achieved and its manifestation in the process, i.e. in data gathered. In addition, since the complete values of information entropy have a unique unit of bit, all elements of the set can be mutually compared. Finally, if needed, complete time-dependence of the information entropy can be substituted with its average value and standard deviation determined within some relatively long, otherwise arbitrary time interval.

\section{Summary and Conclusions}

The model describing dynamics of service-providing company, which is suitable for numerical simulation, is formulated using agent-based modelling. Preliminary results are shown, as a partial contribution to validation of the model.

The information entropy weight is considered as a crucial representative quantity derived from simulated dynamics. That is so because we consider it to be linked with the quality of the service provided. The stated importance the information entropy achieved because it can be calculated using solely data from the simulated model dynamics, without need for external criteria or other parameters. Furthermore, information entropy can be determined for a number of functions characterising dynamics of the modelled system, and several information entropies calculated in that way can be mutually compared. Their comparison reveals what part of the 
modelled dynamics represents in the best (or the worst) way the underlying quality.

\section{References}

[1] Srbljinović, A.; Škunca, O. An Introduction to Agent Based Modelling and Simulation of Social Processes. // Interdisciplinary Description of Complex Systems. 1, 12(2003), pp. 1-8.

[2] Johnston, E.; Kim, Y.; Ayyangar, M. Intending the Unintended: The Act of Building Agent-based Models as a Regular Source of Knowledge Generation. // Interdisciplinary Description of Complex Systems. 5, 2 (2007), pp. 81-91.

[3] Baxter, N.; Collings, D.; Adjali, I. Agent-based modelling intelligent customer relationship management. // BT Technology Journal. 21, 2(2003), pp. 126-132. DOl: 10.1023/A:1024455405112

[4] Kaihara, T. Multi-agent based supply chain modelling with dynamic environment. // International Journal of Production Economics. 85, 2(2003), pp. 263-269. DOI: 10.1016/S09255273(03)00114-2

[5] Terano, T.; Naitoh, K. Agent-Based Modeling for Competing Firms. $/ / 37^{\text {th }}$ Hawai International Conference on Systems Science, Proceedings, 2004.

[6] Kočiško, M.; Novák-Marcinčin, J.; Baron, P.; Dobránsky, J. Utilization of progressive simulation software for optimization of production systems in the area of small and medium companies. // Tehnički vjesnik-Technical Gazette. 19, 4(2012), pp. 983-986.

[7] Krstić Vukelja, E.; Runje, B. Quality Service Evaluation through the System of Complaints and Praise. // Interdisciplinary Description of Complex Systems. 12, 1(2014), pp. 78-91. DOI: 10.7906/indecs.12.1.5

[8] Liu, P.; Zhang, X. Research on the supplier selection of a supply chain based on entropy weight and improved ELECTRE-III method. // International Journal of Production Research. 49, 3(2011), pp. 637-646. DOl: 10.1080/00207540903490171

[9] Zhang, H., et al. The evaluation of tourism destination competitiveness by TOPSIS \& information entropy - A case in the Yangtze River Delta of China. // Tourism Management. 32, 2(2011), pp. 443-451. DOI: 10.1016/j.tourman.2010.02.007

[10] Letic, D.; Davidovic, B.; Zivkovic, D. Z. Simulation of risk based on ending activities of the design plan using special function. // Tehnički vjesnik-Technical Gazette. 20, 4(2013), pp. 615-620.

[11] Stepanić, J.; Sabol, G.; Žebec, M. S. Describing social systems using social free energy and social entropy. //

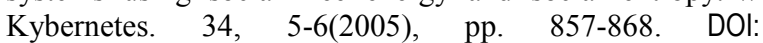
10.1108/03684920510595535

[12] Kasač, J.; Štefančić, H.; Stepanić, J. Comparison of social and physical free energies on a toy model. // Physical Review E 70(1) Part 2, No. 016117, 2004,

[13] Gray, R. M. Entropy and Information Theory, $2^{\text {nd }}$ edition. Springer, 2011. DOI: 10.1007/978-1-4419-7970-4

\section{Authors' addresses}

Biserka Runje, PhD, Prof.

Sveučilište u Zagrebu, Fakultet strojarstva i brodogradnje

Ivana Lučića 1, 10000 Zagreb, Croatia

E-mail: biserka.runje@fsb.hr

Elizabeta Krstić Vukelja, MSc

Stomatološka poliklinika Zagreb

U1. Ivana Perkovca 3, 10000 Zagreb, Croatia

ekrstic@spz.hr
Josip Stepanić, PhD, Assoc. Prof.

Sveučilište u Zagrebu, Fakultet strojarstva i brodogradnje Ivana Lučića 1, 10000 Zagreb, Croatia

E-mail: josip.j.stepanic@fssb.hr 